\title{
New horizons for the repair of
} skin defects

To the Editor: Visible skin defects in adults, and especially those in the developing child, are frequently very unsightly, stigmatising the person and often leading to severe psychological sequelae. This situation can result from surgical treatment of vitiligo, congenital pigmented naevi, vascular hamartomas and skin cancer, and from burn scars and contractures. Many affected people are ostracised from society because of our inability to restore the defect to normality after excision, or at least to an acceptable functional and cosmetic end result. The obvious solution is to replace the excised tissue with a functional and cosmetic substitute similar to the surrounding area.

An assortment of dermal substitutes is currently commercially available to replace these surgical defects. They usually require a period of 2 - 3 weeks to vascularise before an epithelial autologous skin graft can be done to complete the process.

The Tissue Biology Research Unit at Zurich University has, through the EuroSkinGraft Consortium Project, developed a bioengineered full-thickness skin graft containing dermal and epidermal equivalent components including preformed blood capillaries and melanocytes. ${ }^{[1-6]}$ While these grafts lack innervation, hair follicles and sweat glands, they are the most complete bioengineered skin grafts currently available to treat full-thickness skin defects resulting from acute and elective procedures. In preclinical trials, rapid take, almost no shrinkage of the graft and excellent non-scar remodelling of the skin transplant were achieved. ${ }^{[3,4]}$

Disfigured people have a burning desire to be normal again. A prevascularised pigmented graft would be of immense value in surgery performed on darker-skinned people suffering from a broad spectrum of disfiguring skin defects. It would be indispensable in surgical correction of the depigmented areas of crippling vitiligo or healed burn wounds (subject to squamous carcinoma), or to reconstruct skin defects following scar and keloid excisions or contracture release and repair as a single-stage procedure, without delaying autologous skin grafting. The repaired area would have the same physical appearance as the surrounding unaffected skin. In the future, repair of such defects with equivalent pigmented skin will be considered essential to optimise functional and cosmetic outcomes, and it will be of indispensable value to those affected.

Pigmented skin-equivalent grafts for patients with darker skins have been achieved successfully in experimental circumstances, but have not been subject to clinical trials. This is an essential regenerative concept with wide therapeutic and practical advantages for the future.

H Rode

Department of Paediatric Surgery, Red Cross War Memorial Children's Hospital and Faculty of Health Sciences, University of Cape Town, South Africa heinz.rode@uct.ac.za

1. Biedermann T, Bottcher-Haberzeth S, Klar AS, et al. Rebuild, restore, reinnervate: Do human tissue engineered dermo-epidermal skin analogs attract host nerve fibers for innervations? Pediatr Surg Int 2013;29(1):71-78. [http://dx.doi.org/10.1007/s00383-012-3208-1] 
2. Bottcher-Haberzeth S, Klar AS, Biedermann T, et al. 'Trooping the colour': Restoring the original donor skin colour by addition of melanocytes to bioengeneered skin analogs. Pediatr Surg Int 2013:29(3):239427. [http://dx.doi.org/1007/s00383-012-3217-0]

3. Hartmann-Fritsch F, Biedermann T, Braziulis E, Meuli M, Reichmann E. A new model for preclinical testing of dermal substitutes for human skin reconstruction. Pediatr Surg Int 2013;29(5):479-488 [http://dx.doi.org/10.1007/s00383-013-3267-y]

4. Marino D, Reichmann E, Meuli M. Skingineering. Eur J Pediatr Surg 2014;24(3):205-213. [http:// dx.doi.org/10.1055/s-0034-1376315]

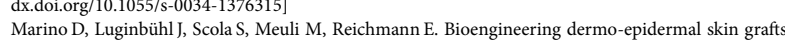
Marino D, Luginbühl J, Scola S, Meuli M, Reichmann E. Bioengineering dermo-epidermal skin grafts
with blood and lymphatic capillaries. Sci Transl Med 2014;6(221):221 ra14. [http://dx.doi.org/10.1126/ scitranslmed.3006894]

6. Klar AS, Böttcher-Haberzeth S, Schiestl C, Reichmann E, Meuli M. Tissue-engineered dermoepidermal skin analogs exhibit de novo formation of a near natural neurovascular link 10 weeks after transplantation. Pediatr Surg Int 2014;30(2):165-172. [http://dx.doi.org/10.1007/s00383-013-3446-x]

S Afr Med J 2015;105(7):514-515. DOI:10.7196/SAMJnew.7807 